\title{
Retraction
}

\section{Retracted: Physical Activity: An Important Adaptative Mechanism for Body-Weight Control}

\author{
International Scholarly Research Notices
}

Received 12 March 2017; Accepted 12 March 2017; Published 2 July 2017

Copyright (C) 2017 International Scholarly Research Notices. This is an open access article distributed under the Creative Commons Attribution License, which permits unrestricted use, distribution, and reproduction in any medium, provided the original work is properly cited.

International Scholarly Research Notices has retracted the article titled "Physical Activity: An Important Adaptative Mechanism for Body-Weight Control" [1]. The article was found to contain a substantial amount of material from the following published articles: "Tappy, L., Binnert, C. and Schneiter, P. (2003) 'Energy expenditure, physical activity and body-weight control', Proceedings of the Nutrition Society, 62(3), pp. 663-666. doi: 10.1079/PNS2003280," "James A. Levine: Nonexercise activity thermogenesis (NEAT): environment and biology American Journal of Physiology Endocrinology and Metabolism Published 1 May 2004 Vol. 286 no. 5, E675-E685 DOI: 10.1152/ajpendo.00562.2003," and "Stephen A Harrison, Christopher Paul Day: Recent advances in clinical practice: Benefits of lifestyle modification in NAFLD. Gut 2007;56:12 1760-1769 Published 2 October 2007 doi: 10.1136/gut.2006.112094." The first author Carmine Finelli accepts responsibility for this and apologizes to Tappy et al., Levine, and Harrison and Day.

Updated August 17, 2017, to include the similarity with Harrison and Day.

\section{References}

[1] C. Finelli, S. Gioia, and N. La Sala, "Physical activity: an important adaptative mechanism for body-weight control," ISRN Obesity, vol. 2012, Article ID 675285, 5 pages, 2012. 